- There is a need to study suitable alternatives to amalgam for use in primary teeth.

- This was a comparative study to evaluate the performance of Dyract and amalgam for restoration of minimal proximal caries removed after administration of local analgesia in primary teeth.

- Evaluation of restorations for recurrent caries, wear, marginal integrity and surface texture showed that Dyract performed slightly better than amalgam, though significantly only for marginal integrity.

- Dyract is a suitable alternative to amalgam both in general dental practice and a specialist environment when used for restoration of minimal proximal caries.

\title{
Clinical performance of a compomer and amalgam for the interproximal restoration of primary molars: a 24-month evaluation
}

\author{
M. S. Duggal ${ }^{1}$ K. J. Toumba ${ }^{2}$ and N. K. Sharma ${ }^{3}$
}

\begin{abstract}
Objectives To evaluate the clinical performance of a compomer material (Dyract ${ }^{\circledR}$ ) in comparison with dental amalgam (Contour ${ }^{\circledR}$ ) for management of proximal caries in primary molars in young children. Setting General dental practice, and a dental hospital paediatric clinic. Method This was a prospective study. A split mouth design was used with identical pairs of minimal Class II cavities, of matched tooth type in the same dental arch, usually diagnosed with the use of bitewing radiographs. Seventy-eight pairs of restorations were completed of which 60 pairs were available for evaluation after 24 months.

Results Comparable retention rates were observed for both Dyract and amalgam. The retention rates were high for both materials, with only four amalgam and two Dyract restorations failing over 24 months. Significantly better marginal integrity $(P<0.05)$ was observed for Dyract compared with amalgam with no significant differences between the two materials for recurrent caries, wear or surface texture.

Conclusions Dyract seemed to be a suitable alternative to amalgam for proximal restorations in primary molars of young children for use in general dental practice.
\end{abstract}

Concerns have been expressed with regards to the potential toxicity and aesthetics of dental amalgam with a need therefore to develop an alternative for proximal restoration of primary molars. The survival rates of amalgam restorations in primary teeth have been shown to vary from poor to excellent. ${ }^{1-3}$ Stainless steel crowns (SSCs) have the best longevity, ${ }^{4,5}$ although, their use by general dental practitioners in the UK has been shown to be very low. ${ }^{6}$ Instead GDPs favour glass ionomer cements, composites or amalgam as the materials of choice when restoring primary teeth. These materials are relatively quick and easy to use and therefore help to minimize the duration of the treatment session for the child patient. The durability of materials used for restoration of primary molars has been

\footnotetext{
${ }^{1}$ Professor of Child Dental Health, ${ }^{2}$ Senior Lecturer in Child Dental Health, Child Dental Health, Leeds Dental Institute, Leeds; ${ }^{3}$ GDP, 19 Cemetery Road, Heckmondwike, West Yorkshire, UK

Correspondence to: Professor M. S. Duggal, Division of Child Dental Health, Leeds Dental Institute Leeds LS2 9LU

E-mail:m.s.duggal@leeds.ac.uk
}

\section{Refereed paper}

Received 13.12.01; Accepted 23.04.02

๑ British Dental Journal 2002; 193: 339-342 reviewed by Kilpatrick ${ }^{7}$ who highlighted the great variability in the success rates, and that these success rates are affected by the age of the child at time of treatment, ${ }^{8}$ and by the use of local analgesia and rubber dam. ${ }^{9}$ Kilpatrick $^{7}$ also reported that the long-term failure rate of composites (62\%) and glass ionomer cements $(67 \%)$ is high whereas for amalgam it is relatively low (20\%).

The 1993 child dental health survey in the United Kingdom ${ }^{10}$ showed that the proportion of filled teeth for the primary dentition has decreased despite an increase in the decayed component. Therefore, there was a need for a good quality, long lasting and 'user friendly' restorative material in paediatric dentistry. Compomers seem to fulfil these requirements for the restoration of Class II cavities in primary molars. Initial results (6 months followup) using compomers for the restoration of primary molars were promising. ${ }^{11}$ Studies using longer follow-up periods have shown that this material indeed lived up to its early promise and good survival rates have been reported for restorations in primary molars. ${ }^{3,12-14}$ However most studies reported in the literature have been on restorations performed by specialists in paediatric dentistry and not in general dental practice. In the United Kingdom most children are treated by general dental practitioners who are not specialists in paediatric dentistry. It was therefore thought important to evaluate the performance of such restorations in these services in addition to those provided by specialists. Therefore the aim of the study was to evaluate the clinical performance of a compomer material (Dyract) in comparison with dental amalgam for Class II restorations in primary molars carried out in general dental practice, and a dental hospital paediatric clinic.

\section{MATERIALS AND METHODS}

Children aged 4-7 years with pairs of minimal Class II cavities of their primary molars were selected for inclusion into this prospective study. Informed consent was obtained from the parents and ethical approval was granted by the regional ethics committee. Children were included in the study if their behaviour rating scores was 3 or 4 on the Frankl scale. ${ }^{15}$ This was necessary because all restorations were placed with the use of local analgesia. A split mouth design with identical pairs of minimal Class II cavities, of matched tooth type in the same dental arch, diagnosed with the use of bitewing radiographs, was used. 
The principal investigators placed 78 pairs of matched restorations. These were carried out in a general dental practice and at the dental institute paediatric dental clinic. All of the restorations were performed under standardised conditions using topical and local anaesthesia, but not rubber dam. Matrix bands and wedges were used together with cotton wool roll isolation for restoration placement. The paired cavities were restored with compomer (Dyract ${ }^{\circledR}$ ) or amalgam alloy material (Contour ${ }^{\circledR}$ ), and the assignment of right and left cavities to each material was done by the use of random allocation tables. Each child in the study had pairs of bitewing radiographs taken at baseline. Further radiographs were only taken if there was a clinical indication and not for the purposes of the study. Each pair of restorations was clinically assessed at six monthly intervals according to the criteria used by the United States Public Health Service (USPHS). ${ }^{16}$ The USPHS is the most commonly used system in the literature used in studies that have compared restorative materials in primary teeth. All data were recorded onto recording forms and then entered onto a computer for statistical analysis.

The investigators who placed the restorations attended calibration sessions carried out at regular intervals to standardise the diagnosis of carious lesions, the placement of the restorations and the evaluation of the restorations at follow-up visits. Diagnosis of minimal Class II lesions for inclusion in the study was also standardised. Standardisation of $\mathrm{x}$-ray technique for bitewing radiographs using Rinn holders and the extended cone paralleling technique was performed. The technique for placement of the restorations was standardised using plastic and extracted primary molar teeth.

Minimal Class II undercut box preparations with occlusal keys only for amalgam restorations were used for cavity design and no lining materials were used. Matrix bands and wedges were used. The compomer (Dyract) and amalgam alloy (Contour) were used according to the manufacturer's instructions, and the investigators were standardised for the mixing and handling properties of the two materials.

Finally, each of the investigators was calibrated for the evaluation of the restorations at follow-up visits according to the criteria used by the United States Public Health Service ${ }^{16}$ for marginal integrity, wear, surface texture and recurrent caries. The investigators were recalibrated for the evaluation criteria on an annual basis. In addition, 10\% of each investigator's sample was also evaluated by another investigator to assess the interexaminer reproducibility of the clinical assessment of the restorations by calculating the kappa score.

\section{Statistical analysis}

Statistical analysis was performed using the McNemar test of change for longitudinal assessments. In addition a Wilcoxon Signed test was used to study differences between the two materials at 6,12, 18 and 24 month follow-up periods. Values of $P<0.05$ were accepted as statistically significant.

\section{RESULTS}

In total 78 pairs of restorations were placed in the Leeds Dental Institute and in a general dental practice. Eighteen pairs were lost to follow-up and 60 pairs were available for a 24-month evaluation. Of the 60 pairs that completed the study, 22 pairs of restorations were in lower second primary molars, 28 in the lower first primary molars and 10 pairs in upper second primary molars. Cohen's Kappa value for inter-examiner reproducibility was excellent (0.91).

\section{Recurrent caries}

The results for the prevalence of recurrent caries with the two restorations at 6,12, 18 and 24 months are presented in Table 1. At 18 months and 24 months a slightly higher prevalence of recurrent caries was seen in teeth restored with amalgam compared with Dyract. However, this difference was not statistically significant.

\section{Loss of substance (wear)}

There were small differences, though not significant after 24 months with 66.6\% and 71.6\% of amalgams and Dyract respectively, not showing any wear (Table 2). An almost complete wear of the restorations, as evident by the exposure of the base of the

Table 1 Comparison of the recurrent caries with Dyract and amalgam at 6, 12, 18 and 24 months after placement of the restorations

\begin{tabular}{|c|c|c|c|c|c|c|c|c|}
\hline & \multicolumn{8}{|c|}{ Follow-up period } \\
\hline & \multicolumn{2}{|c|}{6 months } & \multicolumn{2}{|c|}{12 months } & \multicolumn{2}{|c|}{18 months } & \multicolumn{2}{|c|}{24 months } \\
\hline & A & B & A & $\mathrm{B}$ & A & B & A & B \\
\hline \multicolumn{9}{|l|}{ Amalgam } \\
\hline No. of restorations & 60 & 0 & 60 & 0 & 54 & 6 & 51 & 9 \\
\hline$(\%)$ & 100 & 0 & 100 & 0 & 90 & 10 & 85 & 15 \\
\hline \multicolumn{9}{|l|}{ Dyract } \\
\hline No. of restorations & 60 & 0 & 60 & 0 & 57 & 3 & 54 & 6 \\
\hline$(\%)$ & 100 & 0 & 100 & 0 & 95 & 5 & 90 & 10 \\
\hline
\end{tabular}

$A=$ No recurrent caries

$\mathrm{B}=$ Visual evidence of dark deep discolouration

Table 2 Comparison of the contour or loss of substance (wear) of Dyract and amalgam at 6, 12, 18 and 24 months after placement of the restorations

\begin{tabular}{|c|c|c|c|c|c|c|c|c|c|c|c|c|}
\hline & \multicolumn{12}{|c|}{ Follow-up period } \\
\hline & \multicolumn{3}{|c|}{6 months } & \multicolumn{3}{|c|}{12 months } & \multicolumn{3}{|c|}{18 months } & \multicolumn{3}{|c|}{24 months } \\
\hline & A & B & C & A & B & C & A & B & C & A & B & C \\
\hline \multicolumn{13}{|l|}{ Amalgam } \\
\hline No. of restorations & 51 & 9 & 0 & 47 & 13 & 0 & 43 & 14 & 3 & 40 & 16 & 4 \\
\hline$(\%)$ & 85 & 15.0 & 0.0 & 78.3 & 21.6 & 0.0 & 71.6 & 23.3 & 5.0 & 66.6 & 26.6 & 6.6 \\
\hline \multicolumn{13}{|l|}{ Dyract } \\
\hline No. of restorations & 50 & 10 & 0 & 50 & 10 & 0 & 46 & 13 & 1 & 43 & 15 & 2 \\
\hline$(\%)$ & 83.3 & 16.6 & 0.0 & 83.3 & 16.6 & 0.0 & 76.6 & 21.6 & 1.6 & 71.6 & 25.0 & 3.3 \\
\hline
\end{tabular}

A $=$ Restoration continuous with existing anatomic form

$B=$ A surface concavity is evident

C $=$ Loss of restorative substance with the base or dentine exposed 


\begin{tabular}{|c|c|c|c|c|c|c|c|c|c|c|c|c|}
\hline & \multicolumn{12}{|c|}{ Follow-up period } \\
\hline & \multicolumn{4}{|c|}{6 months } & \multicolumn{2}{|c|}{12 months } & \multicolumn{3}{|c|}{18 months } & \multicolumn{3}{|c|}{24 months } \\
\hline & A & B & C & A & B & C & A & B & C & A & B & C \\
\hline \multicolumn{13}{|l|}{ Amalgam } \\
\hline No. of restorations & 51 & 9 & 0 & 49 & 11 & 0 & 46 & 14 & 0 & 40 & 18 & 2 \\
\hline$(\%)$ & 85 & 15 & 0 & 81.6 & 18.3 & 0 & 76.6 & 23.3 & 0 & 66.6 & 30.0 & 3.3 \\
\hline \multicolumn{13}{|l|}{ Dyract } \\
\hline No. of restorations & 58 & 2 & 0 & 52 & 7 & 1 & 49 & 10 & 1 & 49 & 10 & 1 \\
\hline$(\%)$ & $96.6^{*}$ & $3.3^{*}$ & 0 & 86.6 & 11.6 & 1.6 & 81.6 & 16.6 & 1.6 & $81.6^{*}$ & $16.6^{*}$ & 1.6 \\
\hline
\end{tabular}

$A=$ No visible crevice along periphery of restoration

$B=$ Edge of restoration does not adapt closely to tooth structure as evident on probing

$\mathrm{C}=$ Explorer penetrates crevice depth to A-D junction

${ }^{*} p<0.05$

Table 4 Comparison of the surface texture of Dyract and amalgam at 6, 12, 18 and 24 months after placement of the restorations

\begin{tabular}{|c|c|c|c|c|c|c|c|c|c|c|c|c|}
\hline & \multicolumn{12}{|c|}{ Follow-up period } \\
\hline & \multicolumn{3}{|c|}{6 months } & \multicolumn{3}{|c|}{12 months } & \multicolumn{3}{|c|}{18 months } & \multicolumn{3}{|c|}{24 months } \\
\hline & A & B & C & A & B & C & A & B & C & A & B & C \\
\hline \multicolumn{13}{|l|}{ Amalgam } \\
\hline No. of restorations & 56 & 4 & 0 & 56 & 4 & 0 & 52 & 4 & 4 & 47 & 8 & 5 \\
\hline$(\%)$ & 93.3 & 6.7 & 0 & 93.3 & 6.7 & 0 & 86.6 & 6.6 & 6.6 & 78.3 & 13.3 & 8.3 \\
\hline \multicolumn{13}{|l|}{ Dyract } \\
\hline No. of restorations & 52 & 8 & 0 & 52 & 7 & 1 & 50 & 10 & 0 & 48 & 12 & 0 \\
\hline$(\%)$ & 86.6 & 13.3 & 0 & 86.6 & 11.6 & 1.6 & 83.3 & 16.6 & 0 & 80.0 & 20.0 & 0 \\
\hline
\end{tabular}

$\mathrm{A}=$ Surface texture similar to that of polished enamel as determined by an explorer

$B=$ Surface texture gritty

$\mathrm{C}=$ Surface pitting sufficiently coarse to inhibit continuous movement of explorer

cavity or the lining, was found in 6.6\% of the amalgam restorations as compared with 3.3\% of Dyract restorations. This difference was also not statistically significant.

\section{Marginal integrity}

It can be seen from Table 3 that six months after placement, 85\% of amalgam restorations were found to have no visible crevice along the periphery of the restoration as compared with $96.6 \%$ of Dyract. This difference was significant $(P<0.05)$. Also, at 6 month recall it was found that 15\% of amalgam restorations did not adapt closely to the tooth structure as compared with only 3.3\% of Dyract restorations. This difference was also significant $(P<0.05)$. The marginal integrity of Dyract was also significantly better $(P<0.05)$ at 24 months as compared with amalgam restorations.

\section{Surface texture}

There were no significant differences between amalgam and Dyract at any of the follow-up periods (Table 4).

\section{Comparison of the overall retention rates of Dyract and amalgam}

The overall retention rates are shown in Figure 1. At 12 months, slightly lower complete retention rates were observed for amalgam (76.6\%) as compared with dyract (83.3\%). However, this difference was not statistically significant. At the end of 24 months $66.6 \%$ of amalgam restorations were still fully in place as compared with $71.6 \%$ of Dyract, the difference not being statistically significant.

\section{DISCUSSION}

It is important to study longevity of restorative materials not only in an academic or specialist environment but also in general dental practice. Such studies comparing the outcomes of compomers and amalgam over 24 months are still few in the literature, though well conducted studies with fewer numbers have recently been report- ed. ${ }^{3,12}$ However, in these two studies the restorations were placed with the use of rubber dam. It is well known that the use of rubber dam in general dental practice in the UK is very low, especially in children, with under 5\% of dentists reporting its use routinely. ${ }^{6}$ Although it might be considered good clinical practice to use rubber dam for restorative care in children, it would be naïve to believe that general dental practitioners will ever routinely use this in their practice for placing routine restorations in primary teeth. There are few studies on the clinical evaluation of amalgam and compomers where restorations were placed, without the use of rubber dam but also in general dental practice. Our study shows that the clinical outcome for both amalgam and Dyract were comparable when used for proximal restorations in young children, placed both in a specialist setting and in general dental practice and without the use of rubber dam. Some 38 out of a total of 78 pairs of restorations were placed in general dental practice. Because of the stringent inclusion criteria the case mix between general practice and hospital was similar. It was also interesting to note that there were no significant differences in any of the measured outcome parameters for restorations placed in either general dental practice or hospital.

We found an excellent overall retention rate for both amalgam and Dyract after 24 months. Some $66.6 \%$ of amalgam and $71.6 \%$ of Dyract restorations were fully retained with another $26.6 \%$ and $25.0 \%$ of amalgam and Dyract respectively being partially retained. The partially retained restorations were functionally acceptable and did not warrant replacement. This meant that only $6.6 \%$ of amalgam and 3.3\% of Dyract restorations were completely lost during the study. However, it must be remembered that teeth were carefully chosen for inclusion in this study. Only minimal proximal caries, diagnosed on bitewing radiographs in many instances were included in the study. Also, the cavity design was standardised, though it could be argued that the occlusal key made for the amalgam restoration would have made the cavities more extensive compared with those for Dyract and thus influenced the 


\section{Number retained}

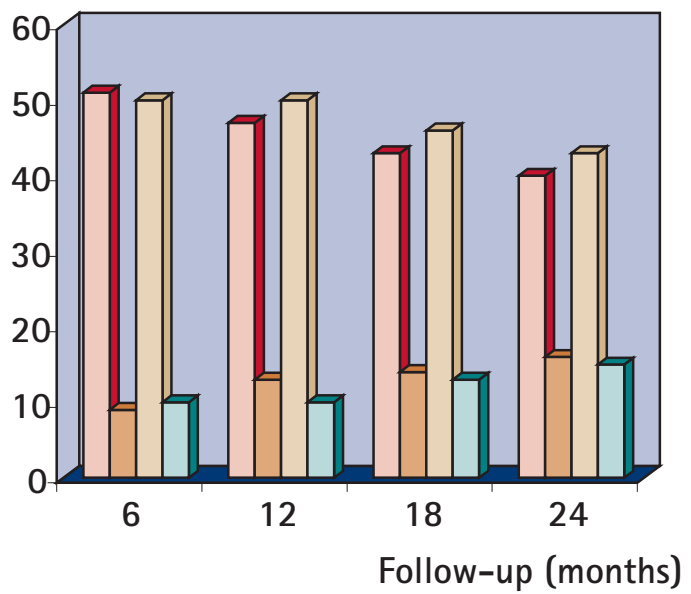

$\square$ Amalgam fully retained

$\square$ Amalgam partially retained

$\square$ Dyract fully retained $\square$ Dyract partially retained
Fig. 1 Comparison of the overall complete and partial retention of Dyract and amalgam at 6, 12, 18 and 24 months after placement of the restorations
It is also interesting to note that Dyract performed slightly better than amalgam for all the parameters that were studied, though no statistical significance was found except for marginal adaptation. This would mean that compomers such as Dyract would be suitable alternatives to amalgam restorations. Dental amalgam has been the mainstay of restorative treatment for the primary dentition for many decades. ${ }^{17}$ However, given the recent concerns about the safety and environmental impact of its use, many dental practitioners and indeed patients might opt not to use amalgam especially in children. Dyract seems to be a suitable alternative to amalgam for proximal restorations in primary molars of young children for use in general dental practice.

This study was funded by the BDA Shirley Glasstone Hughes Memorial Prize. dental practice was comparable with that reported in the literature where the operators were specialists in paediatric dentistry. ${ }^{14}$ There is published data on the clinical evaluation of compomers over 42 months which showed a very high survival rate for Dyract compared with a glass ionomer cement. ${ }^{13}$ However, the sample in that study included both occlusal and proximal restorations. Also, some restorations in the study reported by Welbury et al. ${ }^{13}$ were placed under general anaesthesia excluding any effect that patient cooperation might have on the success rates. These factors might have influenced the overall survival figures in their study.

Complete marginal adaptation, as evidenced by no visible crevice along the periphery of the restoration, was significantly better for Dyract compared with amalgam $(P<0.05)$. Also, restorations where the edge of the restoration did not adapt closely to the tooth structure but the restoration was otherwise functionally acceptable was also significantly higher for Dyract $(P<0.05)$. Both cavities were prepared using similar principles of cavity design. It could be inferred that the adhesive properties of Dyract, which was used in conjunction with the adhesive recommended by the manufacturers, could account for the better marginal properties than amalgam which relies purely on mechanical retention. However, it must be noted that complete loss of marginal adaptation occurred only in two (3.3\%) amalgam and one (1.6\%) Dyract restoration. There was no statistically significant difference between Dyract and amalgam for recurrent caries, wear or surface texture.

Even though rubber dam was not used in this study, all cavity preparations were carried out after administration of local analgesia. It is important to stress that cavity preparation, placement of a matrix band and wedge can produce pain and discomfort. If local analgesia had not been used it could have affected patient co-operation and could have negatively influenced the results of our study.
Braff M H. A comparison between stainless steel crowns and multi-surface amalgams in primary molars. J Dent Child 1975; 42: 474-478.

2 Levering $N \mathrm{~J}$, Messer L B. The durability of primary molar restorations: I. Observations and predictions of success of amalgams. Paediatr Dent 1988;10: 74-80.

3 Marks LA M, Weerheim K L, van Amerongen W E et al. Dyract versus Tytin class II restorations in primary molars: 36 month evaluation. Caries Res 1999; 33: 387-392.

4 Papathanasiou A G, Curzon M E J, Fairpo C G. The influence of restorative material on the survival rate of restorations in primary molars. Paediatr Dent 1994; 16: 282-288.

5 Randall R C, Vrijhoef M A, Wilson N H. Efficacy of preformed metal crowns vs. amalgam restorations in primary molars: A systematic review. J Am Dent Assoc 2000; 131:337-343.

6 Curzon M E J, Fairpo C G, Heathcote D. The use of paedodontic techniques by general dental practitioners and community dental officers - a survey in Yorkshire. J Paediatr Dent 1986; 2: 13-19.

7 Kilpatrick N M. Durability of restorations in primary molars. J Dent 1993: 21:67-73.

8 Holland IS, Walls A W G, Wallwork M A, et al. The longevity of amalgam restorations in deciduous molars. Br Dent J 1986; 161: 255-258.

9 Roberts J F, Sheriff M. The fate and survival of amalgam and preformed restorations placed in a specialist paediatric dental practice. BrDent J 1990; 169: 237-244.

10 Office of Population Censuses and Surveys (OPCS). Dental disease among children in the United Kingdom in 1993. OPCS Monitor 1994. London: HMSO.

11 Krejci I, Gebauer L, Hausler T, et al. Composite polymers-an amalgam substitute for deciduous tooth cavities? (German) Schhweizer Monatsschrift fur Zahnmedizin 1994 104: 724-730.

12 Mass E, Gordan M, Fuks A B. Assessment of compomer proximal restorations in primary molars: A retrospective study. J Dent Child 1999; 66: 93-97.

13 Welbury R R, Shaw A J, Murray J J, et al. Clinical evaluation of paired compomer and glass ionomer restorations in primary molars: final results after 42 months. Br Dent J 2000; 189: 93-97.

14 Fuks A B, Araujo F B, Osorio L B, et al. Clinical and radiographic assessment of class II esthetic restorations in primary molars. Paedr Dent 2000; 22: 479-485.

15 Frankl S H, Shiere R, Fogels H P. Should the parent remain with the child in the dental operatory? J Dent Child 1962; 29: 150-163.

16 Cvar J F, Ryge G. Criterion for the clinical evaluation of dental restorative materials. USPHS Publication No 790-244 San Francisco 1971. United States Government Printing Office.

17 Hse K M Y, Wei S H. Clinical evaluation of compomer in primary teeth:1 year results. J Am Dent Assoc 1997; 128: 1088-1096. 